Revista de Economia Política, vol. 33, $n^{\circ} 1$ (130), pp. 82-101, janeiro-março/2013

\title{
Taxa de câmbio, exportações e crescimento: uma investigação sobre a hipótese de doença holandesa no Brasil
}

\author{
MICHELE POLLINE VERÍSSIMO \\ CLÉSIO LOURENÇO XAVIER*
}

Exchange rate, exports and growth: an investigation on the hypothesis of Dutch disease in Brazil. This paper investigates the hypothesis of Dutch disease in Brazil by the existence of a negative relationship between commodity exports and the real exchange rate, and the effects of export specialization in commodities on the Brazilian economic growth from 1999 to 2010 based on VAR model. The evidences suggested an expressive importance of commodities exports in explaining the real exchange rate changes. Moreover, commodities exports shocks were relevant to explain Brazilian economic growth rate changes, which supports the "curse" of natural resources literature.

Keywords: exports; commodities; exchange rate; growth; Brazil.

JEL Classification: F37; F17; O24.

\section{INTRODUÇÃO}

A economia brasileira tem vivenciado, a partir de 2003, um cenário de apreciação cambial conjugado com altos preços internacionais das commodities, maior participação relativa destes bens no saldo comercial, descoberta das reservas de petróleo no pré-sal, exploração dos biocombustíveis, além de uma demanda externa favorável às exportações. Estes fatos têm trazido preocupações para muitos analistas em termos da deflagração da doença holandesa no Brasil. O receio é de

\footnotetext{
* Professora do Instituto de Economia da Universidade Federal de Uberlândia (IEUFU). E-mail: Michele@ ie.ufu.br; Professor do Instituto de Economia da Universidade Federal de Uberlância (IEUFU), Pesquisador e Bolsista de Produtividade do CNPq. E-mail: clesio@ie.ufu.br. Submetido: 25/abril/2011; Aprovado: 2/abril/2012.
} 
que tais acontecimentos possam acarretar uma concentração excessiva de recursos no setor primário da economia, vindo a prejudicar os setores industriais intensivos em tecnologia sofisticada, com reflexos negativos sobre o potencial de crescimento econômico brasileiro no longo prazo.

A doença holandesa (Dutch disease) é definida pela existência de recursos naturais abundantes que geram vantagens comparativas ao país que os possui, levando-o a se especializar na produção destes bens, e não se industrializar ou terminar se desindustrializando, o que inibe o processo de desenvolvimento econômico de longo prazo (Bresser-Pereira, 2008). Nestes termos, a doença holandesa se manifesta em países que obtêm vantagens ricardianas na produção de commodities através da apreciação da taxa de câmbio real em decorrência da entrada de divisas derivadas das exportações deste tipo de produto. Este fato implica a sustentação de uma taxa de câmbio de equilíbrio corrente inferior (apreciada) à taxa de câmbio de equilíbrio industrial que torna competitivas as exportações de bens manufaturados com maior intensidade tecnológica (Bresser-Pereira, 2008). Admitindo-se que a produção dos bens industriais envolve externalidades positivas, efeitos de aprendizado, ou ainda "forward" e "backward linkages", a ausência ou retração deste setor traz sérias consequências em termos da dinâmica tecnológica e ganhos de produtividade, resultando em perdas de "know-how", capacidades locais e plantas produtivas (Gala, 2006).

Diversos trabalhos consideram que a manutenção de uma taxa de câmbio real mais competitiva é importante para alavancar o crescimento das economias. Em adição, é suposto que a especialização das exportações em produtos com tecnologia sofisticada favorece a obtenção de patamares mais elevados de crescimento econômico dado o potencial dinâmico de criação e difusão das inovações e ganhos de produtividade derivados da indústria. Levando em conta tais aspectos, a doença holandesa contribui para a obtenção de níveis de crescimento do produto menores naqueles países que apresentam o problema. Isso ocorre na medida em que a economia passar a lidar com uma apreciação excessiva da taxa de câmbio real, que reforça a especialização da estrutura produtiva e exportadora em setores baseados em recursos naturais caracterizados por menores efeitos de transbordamento (spillovers) e de difusão de conhecimento para as demais atividades econômicas.

A partir desse contexto, este trabalho pretende investigar a hipótese de doença holandesa no Brasil a partir da análise da relação entre taxa de câmbio real, perfil exportador e crescimento econômico. A hipótese subjacente é a de que existem indicativos de doença holandesa no Brasil, os quais se manifestam por meio de uma relação direta entre exportações de commodities e apreciação do câmbio real, e de uma relação inversa entre exportações de commodities e crescimento econômico.

Para a análise destas questões, o trabalho encontra-se organizado em quatro seções, além desta introdução. A segunda seção realiza uma breve revisão da literatura sobre as relações entre perfil exportador, taxa de câmbio e crescimento econômico. A terceira seção descreve o modelo empírico e a abordagem econométrica utilizada. A quarta seção apresenta e discute os resultados obtidos. Por fim, a quinta seção sistematiza as conclusões do trabalho. 


\section{PERFIL EXPORTADOR, TAXA DE CÂMBIO E CRESCIMENTO ECONÔMICO: ASPECTOS TEÓRICOS E EMPÍRICOS}

\section{Abundância em recursos naturais e crescimento econômico}

As características estruturais de economias centradas nos setores primários em meio ao contexto de alta dos preços das commodities e de apreciação cambial podem resultar na especialização das exportações em produtos intensivos em recursos naturais. Este fato pode prejudicar os setores produtores de bens manufaturados, com reflexos perversos sobre a dinâmica de crescimento das economias. A base deste argumento se assenta na análise de que a atividade industrial se caracteriza por qualidades que reforçam o crescimento econômico no longo prazo, tais como em Kaldor, o qual aponta que a indústria possui retornos crescentes de escala na produção, fortes efeitos de encadeamento para a frente e para trás na cadeia produtiva, efeitos de aprendizado e de difusão de progresso tecnológico, além de possuir maior elasticidade renda das importações do que os produtos primários, permitindo o relaxamento da restrição externa ao crescimento de longo prazo (Oreiro e Feijó, 2010).

A relação entre as exportações de produtos baseados em recursos naturais e os níveis de crescimento alcançados pelas economias tem sido bastante investigada pela literatura. Neste contexto, Sachs e Warner (1995) argumentam que economias ricas em recursos naturais apresentam menores taxas de crescimento no longo prazo do que as economias pobres em tais recursos. Este resultado está vinculado às seguintes hipóteses: i) os países ricos em recursos naturais tendem a desenvolver políticas protecionistas, com burocracia e ineficiência na utilização dos recursos, $o$ que acarreta menores taxas de investimento, e, consequentemente, menores taxas de crescimento econômico; ii) a tendência secular de declínio da relação entre os preços das exportações dos produtos primários e dos manufaturados, e o crescimento mais rápido da demanda por manufaturados comparado aos produtos primários obstaculiza o crescimento baseado em recursos naturais; iii) as exportações de primários possuem baixas ligações para a frente e para trás com os demais setores da economia, enquanto a manufatura desencadeia processos de aprendizado que não se limitam ao interior da firma; e, iv) quanto maior a posse de recursos naturais, maior a demanda por bens não comercializáveis e menor a alocação de capital e trabalho para o setor de manufaturados, o que expande a produção de não comercializáveis, enquanto a produção de manufaturados tende a se encolher. Com base nestas hipóteses, os autores desenvolvem um modelo endógeno de crescimento cross-country que investiga a relação entre exportações baseadas em recursos naturais e taxa de crescimento do PIB no período 1970-1989 e obtêm que uma participação mais elevada das exportações de produtos primários está associada a menores taxas de crescimento econômico.

Collier e Golderis (2007) investigam os efeitos dos preços das commodities agrícolas e não agrícolas sobre o crescimento econômico para 130 países no período 1963-2003 e encontram que os preços das commodities têm efeitos positivos 
sobre o crescimento no curto prazo explicados pelos ganhos de renda real em função da melhoria dos termos de troca. Porém, estes efeitos se tornam significativamente negativos no longo prazo, o que se mostra consistente com a literatura da "maldição" dos recursos naturais, e estão restritos às commodities não agrícolas (petróleo e minerais) e em países com fracas instituições. Os resultados indicam que a sobrevalorização cambial, o alto consumo público e privado, o baixo investimento, e, em menor extensão, a volatilidade dos preços das commodities explicam uma parte substancial da "maldição" dos recursos naturais, fornecendo suporte para a teoria da doença holandesa e para a ideia de que os booms de commodities favorecem a substituição das atividades produtivas pelas atividades rent-seeking.

Cardoso e Holland (2009) analisam o desempenho econômico dos países da América do Sul e considera que a "maldição" dos recursos naturais e a incapacidade da região de se integrar explicam as menores taxas de crescimento econômico destes países quando comparado ao Leste Asiático. Este efeito se baseia em hipóteses como apreciação da taxa de câmbio real decorrente do aumento das exportações baseadas em recursos naturais; investimento insuficiente em educação; fraqueza de instituições; altos gastos públicos; além da fraqueza da política fiscal e da volatilidade dos preços dos principais produtos exportados. Em termos empíricos, os autores obtêm evidências de que mudanças na taxa de câmbio real, nos termos de troca e nos preços das commodities, explicam uma proporção significativa da variação do PIB dos países sul-americanos entre 1980 e 2008.

Em contraponto, existe a defesa de que a descoberta de recursos naturais ou um aumento permanente dos termos de troca pode ser positivo para o desempenho econômico, uma vez que as receitas provenientes da exploração destes recursos permitem a obtenção de níveis mais altos de riqueza e renda, com maior consumo de bens comercializáveis, incluindo importações, além de propiciar receitas para investimento e outros gastos que não poderiam ser realizados em outras circunstâncias. Dessa forma, muitos países ricos em recursos naturais teriam usado suas receitas para desenvolver suas atividades industriais, com a introdução de novas indústrias e tecnologias, contribuindo para a obtenção de níveis mais elevados de crescimento econômico. Sob tais condições, a abundância de recursos naturais não é vista como uma "maldição", mas sim como uma "bênção".

Nesta direção, o trabalho de Lederman e Malloney (2008) rejeita as hipóteses que associam a abundância de recursos naturais a uma "maldição". Estas hipóteses refletem a ideia de que o crescimento em economias ricas em recursos naturais seria prejudicado pela tendência de queda secular dos termos de troca das exportações de primários em relação às exportações de manufaturados; pela baixa produtividade dos fatores utilizados na agricultura; pela baixa intensidade tecnológica dos bens intensivos em recursos naturais e alta volatilidade dos preços destes produtos; e pela fraqueza institucional nos países ricos em recursos naturais. Para os autores, numa visão mais ortodoxa, estes fatores limitadores do crescimento econômico não estão exclusivamente associados à existência de recursos naturais abundantes, podendo ser relacionados a outras questões econômicas, como corrupção ou atividades rent-seeking. 
Sendo assim, Lederman e Malloney (2008) contestam os modelos que obtêm uma relação negativa entre abundância de recursos naturais e crescimento econômico através de dados cross-section e de medidas inadequadas para captar a abundância em recursos naturais (exportações intensivas em recursos/PIB). O uso das exportações líquidas de bens intensivos em recursos naturais por trabalhador para captar a riqueza de recursos naturais e de medidas de qualidade institucional sugere que os recursos naturais podem ter um efeito positivo sobre o crescimento. No entanto, há uma dificuldade de se mensurar a magnitude dos potenciais efeitos benéficos dos recursos naturais sobre o crescimento, e tais efeitos parecem dissipar após controlar as estimações pela volatilidade macroeconômica e acumulação de fatores.

\section{Taxa de câmbio e crescimento econômico}

Vários trabalhos relacionados à literatura sobre câmbio atribuem um papel relevante para as políticas cambiais na alavancagem do crescimento econômico. Neste sentido, é reconhecida a importância da manutenção de uma taxa de câmbio mais competitiva (depreciada) para estimular as exportações e os investimentos. Os países que adotaram essa estratégia tenderam a favorecer seus respectivos processos de crescimento. Neste grupo, podemos citar: Japão e Alemanha no pós-Segunda Guerra, e, nas últimas décadas, China, países do Leste Asiático (Hong Kong, Cingapura, Coreia do Sul e Taiwan) e Índia. De outro lado, muitos países da América Latina e Caribe experimentaram taxas de câmbio sobrevalorizadas e contaram com menores taxas de crescimento econômico no mesmo período.

Neste contexto, Razin e Collins (1997) constroem um indicador de desalinhamento da taxa de câmbio real para 93 países no período 1975-1992, que envolve fatores de longo prazo (fundamentos) e de curto prazo (choques) para verificar se os desvios cambiais do equilíbrio estão relacionados ao desempenho econômico dos países. Os autores estimam equações de crescimento utilizando, além da medida de desalinhamento cambial, variáveis que refletem as condições iniciais dos países (PIB per capita, expectativa de vida e proxies para educação), ambiente externo (termos de troca) e política fiscal (consumo do governo/PIB). Os resultados assinalam que os desalinhamentos da taxa de câmbio real são negativamente associados ao crescimento econômico. O estudo revela uma não linearidade da taxa de câmbio, em que grandes valorizações do câmbio real estão associadas ao menor crescimento econômico, ao passo que desvalorizações moderadas parecem estar associadas ao crescimento mais rápido.

Aguirre e Calderon (2005) argumentam que os desalinhamentos cambiais podem criar distorções nos preços relativos dos bens comercializáveis e não comercializáveis, além de promover uma alocação sub ótima de recursos entre os setores e aumentar a instabilidade macroeconômica, afetando o crescimento econômico. Assim, certos países têm utilizado taxas de câmbio mais depreciadas para melhorar o desempenho do setor exportador e da atividade econômica. Os autores investigam os fundamentos dos desalinhamentos cambiais e os seus impactos sobre o crescimento econômico no período 1965-2003. As evidências obtidas revelam que 
a apreciação do câmbio real de equilíbrio é explicada por aumentos na produtividade relativa, choques favoráveis dos termos de troca, melhor posição dos ativos estrangeiros líquidos e maior razão consumo do governo/PIB. Os efeitos dos desalinhamentos cambiais sobre o crescimento econômico são maiores nos países em desenvolvimento e dependem do tamanho do desvio da taxa de câmbio em relação ao nível de equilíbrio, sendo que o impacto (negativo) da apreciação cambial sobre o crescimento é maior do que o impacto (positivo) de uma desvalorização da taxa de câmbio real.

Gala (2006) discute a hipótese de que câmbios reais mais apreciados estão associados a menores taxas de crescimento econômico. $\mathrm{O}$ autor sinaliza que uma taxa de câmbio mais desvalorizada: i) possibilita a estabilidade do Balanço de Pagamentos, e aumenta a poupança e o investimento; ii) favorece as exportações de bens manufaturados, evitando o problema da doença holandesa; e iii) promove o aumento do emprego e da renda ao permitir o desenvolvimento do setor de comercializáveis. Assim, ao evitar apreciações excessivas do câmbio real pela administração do câmbio nominal, as autoridades monetárias podem contribuir para o desenvolvimento da indústria de manufaturas voltada para a exportação (export-led growth). Em termos empíricos, Gala (2006) analisa a relação entre taxa de câmbio real e crescimento per capita para 58 países em desenvolvimento no período 1960-1999, utilizando variáveis estruturais (capital humano, infraestrutura física e institucional) e macroeconômicas (inflação, sobrevalorização cambial, utilização da capacidade instalada e termos de troca). As evidências apontam que câmbios relativamente desvalorizados estão associados a maiores taxas de crescimento per capita.

Rodrik (2008) também discute a importância da taxa de câmbio real para o crescimento econômico e desenvolve uma análise empírica para 184 países no período 1950-2004. Os resultados indicam que uma taxa de câmbio real desvalorizada é relevante para se estimular o crescimento, especialmente nos países em desenvolvimento. A explicação para esta evidência está associada à fragilidade institucional dos países, que reduz a capacidade do setor privado de se apropriar dos retornos dos investimentos pelas deficiências contratuais, problemas de corrupção, ou ausência de direitos de propriedade. Além disso, as falhas de mercado prejudicam o crescimento dados o vazamento de informações tecnológicas entre as empresas, a necessidade de grandes investimentos para a abertura de novas firmas, a dificuldade de obtenção de financiamento, e os altos salários e ineficiência no mercado de trabalho. Portanto, uma administração inadequada da taxa de câmbio real tem um impacto desfavorável sobre o crescimento econômico, especialmente quando envolve a manutenção de uma taxa de câmbio apreciada por um período de tempo relativamente longo.

Eichengreen (2008) argumenta que a desvalorização cambial não é condição suficiente para alavancar o crescimento econômico, mas deve estar atrelada a outros fundamentos, tais como força de trabalho disciplinada, altas taxas de poupança e de investimento, e influxos de investimento estrangeiro, que permitirão aos países aproveitar as oportunidades para estimular o crescimento. $\mathrm{O}$ autor analisa países industriais e países em desenvolvimento no período 1991-2005, e obtém uma 
relação negativa entre volatilidade da taxa de câmbio real e crescimento econômico. Sendo a taxa de câmbio real um preço relativo, considera-se que esta não pode ser controlada diretamente pelas autoridades, mas pode ser influenciada pelas políticas adotadas em favor da orientação para um crescimento liderado pelas exportações industriais. Porém, uma vez alcançado o objetivo de alavancar o crescimento, tais políticas não devem ser utilizadas indefinidamente, pois causam efeitos colaterais, como inflação, declínio do investimento, elevação dos riscos financeiros e tensões com parceiros comerciais.

Berg e Miao (2010) analisam duas visões sobre o argumento de que a taxa de câmbio real importa para o crescimento econômico. A primeira consiste na visão do Consenso de Washington (CW) de que uma taxa de câmbio valorizada provoca desequilíbrio externo, enquanto uma taxa de câmbio desvalorizada causa desequilíbrio interno e inflação excessiva. A segunda se refere ao trabalho de Rodrik (2008), segundo o qual a manutenção de taxas de câmbio valorizadas prejudica o crescimento econômico, ao passo que uma desvalorização cambial relativamente à Paridade do Poder de Compra (PPC) é positiva para o crescimento porque compensa a fraqueza institucional dos países em desenvolvimento e promove o setor de bens comercializáveis. A análise empírica fornece evidências de que as valorizações cambiais prejudicam o crescimento, enquanto as desvalorizações parecem beneficiar o desempenho econômico, resultados que se mostram consistentes com a visão de Rodrik, mas que requerem algum ajuste em relação à visão do CW.

Outrossim, o autor que efetivamente propiciou centralidade à variável taxa de câmbio como o preço mais estratégico para as economias em desenvolvimento foi Bresser-Pereira (2009, pp. 131-139). Segundo ele, nestas economias existe uma tendência da taxa de câmbio à sobrevalorização, provocada por duas causas estruturais: a doença holandesa e a atratividade que as altas taxas de lucro e de juros existentes nos países em desenvolvimento exercem sobre os fluxos de capitais internacionais. Ressalta-se que a doença holandesa exerce uma intensa pressão na direção da sobrevalorização cambial, mas não leva o país a sofrer déficit em conta-corrente. Por outro lado, a ação da segunda causa estrutural na tendência à sobrevalorização da taxa de câmbio - a atratividade das altas taxas de lucros e de juros nos países em desenvolvimento - relaciona-se diretamente com o ingresso de capital externo e com a persistente política de crescimento com poupança externa, resultando em alta taxa de substituição da poupança interna pela poupança externa e déficit em conta-corrente nos países em desenvolvimento.

\section{Perfil exportador e crescimento econômico}

Alguns estudos sobre o papel da especialização das exportações sobre o crescimento econômico se apoiam na ideia de que, além de se incentivar o volume das exportações através do câmbio depreciado, torna-se relevante considerar o perfil daquilo que é exportado, se o objetivo é atingir taxas mais elevadas de crescimento. Nesta linha, o argumento é o de que o perfil exportador voltado para produtos 
de maior intensidade tecnológica tem contribuído para estimular taxas de crescimento mais elevadas em certos países.

Nesta linha, Dalum, Laursen e Verspagen (1996) testam a hipótese de que a estrutura produtiva de uma economia importa para o crescimento econômico. Os autores reconhecem a importância da tecnologia para o maior crescimento da produtividade, ao passo que a ideia de que os mercados para alguns bens crescem mais rápido do que para outros revela que a especialização naquelas atividades fornece maiores oportunidades para o crescimento. O estudo utiliza dados para a OCDE no período 1965-1988 e constrói índices de especialização para dois grupos de setores produtivos ( high e low tech). As regressões de crescimento são estimadas incluindo, além da especialização, variáveis do lado da oferta (trabalho e capital), e variáveis que representam o papel da tecnologia (patentes) e convergência tecnológica $($ catch-up). Os resultados mostram que os indicadores de especialização foram significativos para várias atividades, exceto nos setores têxtil e de metais básicos. Conclui-se que o crescimento setorial do produto está relacionado com a especialização dentro dos setores ligados aos modelos de comércio internacional.

Hausmann et al. (2005) investigam se os bens comercializáveis associados a níveis mais elevados de produtividade apresentam um desempenho econômico melhor. Para isso, os autores constroem um índice de produtividade (PROD), que considera uma média ponderada do produto per capita dos países que exportam um produto, onde os pesos refletem as vantagens comparativas reveladas de cada país naquele produto. A partir deste indicador, é construído o nível de renda/produtividade (EXPY), que reflete o modelo de especialização do país. O trabalho utiliza dados sobre produtos primários e manufaturados de 40 países. Os resultados indicam que o EXPY é altamente correlacionado com o produto per capita, sendo que países com alto crescimento, como China e Índia, têm níveis de EXPY muito maiores do que aqueles previstos em economias com níveis de renda semelhantes. Tal fato sugere que países especializados na produção e exportação de bens de maior produtividade alcançam níveis de crescimento econômico mais elevado.

Rodrik (2006) analisa a relação entre perfil exportador e crescimento na China. O autor ressalta que o rápido crescimento da economia chinesa não reflete apenas o aumento do volume exportado, em função das medidas de abertura comercial e de uma taxa de câmbio nominal desvalorizada, nem encontra suporte na teoria das vantagens comparativas, em termos da exportação de produtos intensivos em trabalho. A hipótese é a de que o excepcional crescimento da economia chinesa está relacionado à mudança do perfil das exportações em direção a uma cesta de produtos mais sofisticados. Nos testes empíricos, Rodrik (2006) utiliza o índice EXPY e obtém que, ao dobrar o nível de produtividade das exportações, há um aumento de $6 \%$ no crescimento per capita, sendo os ganhos de produtividade decorrentes da produção de um conjunto de bens exportáveis mais sofisticados (produtos eletrônicos). Destaca-se o papel do investimento direto estrangeiro para a evolução da indústria chinesa, uma vez que a entrada destes capitais foi permitida mediante formação de joint ventures e transferência de tecnologia para as firmas domésticas, o que possibilitou a aquisição de capacidades para construir uma in- 
dústria moderna voltada para a exportação de uma cesta de produtos mais sofisticados, impulsionando o crescimento da economia.

A partir das evidências teóricas e empíricas apontadas pela literatura sobre perfil exportador, taxa de câmbio e crescimento econômico, cabe ressaltar a importância da análise dos indicativos de doença holandesa nas economias, uma vez que esta determina que as exportações baseadas em recursos naturais conduzem à apreciação do câmbio real, o que prejudica as exportações dos setores manufaturados e acarreta taxas menores de crescimento no longo prazo. Assim, emerge uma preocupação quanto ao nível da taxa de câmbio real vigente e ao estabelecimento de políticas que visem alterar o perfil exportador das economias ricas em recursos naturais no sentido de se estimular as exportações de produtos manufaturados com maior conteúdo tecnológico, se o objetivo é obter taxas de crescimento mais elevadas ao longo do tempo.

\section{METODOLOGIA E FONTE DE DADOS}

Em consonância com os pressupostos do modelo da doença holandesa, as exportações de commodities são beneficiadas pelas vantagens ricardianas na produção de bens intensivos em recursos naturais, as quais são derivadas do diferencial de produtividade e do fato que os preços destes bens no mercado internacional são definidos pelo produtor menos eficiente admitido no mercado. Tais exportações podem ser estimuladas pela descoberta de uma nova fonte destes recursos ou por uma elevação dos preços destes bens no mercado internacional, implicando entrada de divisas no país, o que tende a promover uma apreciação da taxa de câmbio real.

A entrada de divisas no país rico em recursos pode implicar uma expansão do gasto doméstico em bens e serviços produzidos internamente, o que pressiona os preços e os salários do setor de bens não comercializáveis e reduz a rentabilidade e a produção dos setores não beneficiados com as vantagens ricardianas. Em consequência, a economia direciona os recursos produtivos (capital e trabalho) para os setores intensivos em recursos naturais, expandindo a produção e as quantidades exportadas, ao passo em que se verifica uma queda da produção dos bens manufaturados intensivos em tecnologia (desindustrialização). Ademais, a apreciação cambial dificulta a competitividade externa dos produtos manufaturados que utilizam tecnologia sofisticada, os quais não contam com vantagens ricardianas, e, portanto, necessitam de uma taxa de câmbio mais competitiva (chamada taxa de câmbio de equilíbrio industrial) para se inserirem no mercado internacional. Assim, em função dos efeitos dinâmicos dos setores produtores de bens manufaturados (rendimentos crescentes, externalidades tecnológicas, efeitos de aprendizado), este processo acaba por prejudicar o potencial de crescimento das economias ricas em recursos naturais no longo prazo.

Sob tal contexto, este trabalho utiliza a metodologia de Vetores Auto-Regressivos (VAR) para a estimação de um modelo que permita a obtenção de evidências 
capazes de esclarecer sobre a hipótese de doença holandesa no Brasil no período 1999-2010 nos seguintes termos: i) identificar uma relação (negativa) entre as exportações de commodities e o comportamento da taxa de câmbio real, e ii) averiguar a importância do perfil exportador de commodities para explicar o desempenho econômico brasileiro.

A metodologia VAR é comumente utilizada para a construção de sistemas de previsão de séries temporais inter-relacionadas e para a análise dos impactos dinâmicos dos distúrbios aleatórios sobre o sistema de variáveis que compõem o modelo. Para isso, todas as variáveis são consideradas endógenas, formando um sistema de equações estimadas por Mínimos Quadrados Ordinários (MQO), em que o valor de cada variável é expresso como uma função linear dos valores defasados dela mesma e de todas as outras variáveis incluídas no modelo. Tal metodologia se mostra útil para a análise das interações propostas neste trabalho, na medida em que possibilita a análise das relações dinâmicas entre as variáveis endógenas consideradas, sem a necessidade de se definir a priori a ordem de determinação e a causalidade entre elas. Sendo assim, a metodologia VAR possibilita a análise da interação de variáveis explicativas do desempenho econômico brasileiro e da taxa de câmbio real relacionadas à dinâmica do comércio de commodities, sem que se assuma previamente uma relação causal entre elas.

Um exame mais detalhado das estimações do VAR é comumente realizado através das Funções de Resposta aos Impulsos (FIR) e da Análise de Decomposição de Variância dos Erros de Previsão (ADV). A FIR traça o efeito de um choque no tempo $t$ dos termos de erro de uma variável particular sobre os valores correntes e futuros das variáveis do VAR, mantendo-se todos os outros choques constantes, tendo em vista que um choque para uma variável $y_{t}$ qualquer afeta essa mesma variável e é transmitido para todas as variáveis endógenas através da estrutura dinâmica do VAR. A ADV informa a proporção (em \%) dos movimentos de uma variável que é devida aos seus próprios choques e aos choques dos erros de previsão das outras variáveis do VAR (Stock e Watson, 2001; Enders, 2004).

Para a estimação do modelo VAR proposto, utilizaram-se dados trimestrais referentes ao período 1999-03 a 2010-04 obtidos junto às estatísticas do Banco Central do Brasil (BCB), Ministério do Desenvolvimento, Indústria e Comércio Exterior (MDIC), do Fundo Monetário Internacional (IFS-CDROM) e do banco de dados do Instituto de Pesquisa em Economia Aplicada (IPEADATA). ${ }^{1}$

As variáveis utilizadas nas estimações são:

- $\mathrm{TCPIB}=$ Taxa de crescimento do PIB real brasileiro (em \%)

- TCREF = Taxa de câmbio real efetiva brasileira (índice $2005=100$ )

\footnotetext{
${ }^{1}$ Considera-se que o período 1999-2010 é razoavelmente adequado para a análise proposta, uma vez que o mesmo se caracteriza pela adoção do regime de câmbio flexível no Brasil. Ademais, somente a partir de 2003 é que se verifica uma apreciação cambial significativa acompanhada pelo crescimento contínuo das exportações brasileiras, o que pode ser considerado como "sintoma" de doença holandesa no país.
} 
- $\mathrm{IPCOM}=$ Preços das commodities (índice $2005=100$ )

- $\mathrm{XCOM}=$ Participação das commodities nas exportações totais (em \%)

- TCPIBEUA = Taxa de crescimento do PIB real americano (em \%)

O modelo estimado neste trabalho se encontra fundamentado na equação básica de determinação do produto nacional, expressa a seguir:

$$
Y=C+I+G+(X-M) \quad \text { (eq. } 1)
$$

Onde:

$\mathrm{Y}=$ Produto nacional

$\mathrm{C}=$ Consumo agregado

$\mathrm{I}=$ Investimento agregado

$\mathrm{G}=$ Gastos do governo

$(\mathrm{X}-\mathrm{M})=$ Exportações líquidas

A partir da equação de determinação do produto nacional, o modelo VAR supõe que os impactos do consumo, investimento, gastos do governo e importações sobre o produto nacional são exógenos (inalterados) ao longo do período estudado. A finalidade dos modelos VAR consiste em captar os efeitos das exportações de commodities e de alguns de seus fatores determinantes (preços, câmbio e demanda externa) sobre o crescimento do produto brasileiro. Neste âmbito, o seguinte modelo é estimado:

Modelo VAR: TCPIB, XCOM, TCREF, IPCOM, TCPIBEUA

Portanto, o objetivo do modelo é identificar relações entre a taxa de crescimento do PIB brasileiro, a taxa de câmbio real e as exportações totais de commodities, considerando também os efeitos determinados pelos preços das commodities e pela demanda externa no período pós-flexibilização cambial (1999-2010).

\section{RESULTADOS}

\section{Testes de estacionariedade e seleção dos modelos VAR}

A estimação dos modelos VAR pressupõe a realização dos testes de estacionariedade das séries. Quando as séries são estacionárias, os efeitos de choques inesperados são dissipados ao longo do tempo e as séries são reversíveis para o nível médio de longo prazo (Bueno, 2008).

O diagnóstico da estacionariedade das séries analisadas foi baseado na aplicação dos testes Augmented Dickey-Fuller (ADF) e Phillips-Perron (PP), cujos resultados estão sistematizados na Tabela 1 .

Os resultados indicam a não rejeição da hipótese nula de raiz unitária para as variáveis taxa de câmbio real efetiva (TCREF), preços das commodities (IPCOM) e exportações de commodities (XCOM). Estas variáveis se tornam estacionárias 
quando tomadas em primeira diferença, sendo, portanto, integradas de ordem 1. De outro lado, os testes indicam a rejeição da hipótese nula de raiz unitária para as variáveis taxa de crescimento do PIB real brasileiro (TCPIB) e taxa de crescimento do PIB real americano (TCPIBEUA) em nível, revelando que as mesmas podem ser consideradas integradas de ordem zero.

Tabela 1: Testes de Raiz Unitária

\begin{tabular}{l|c|c|c|c|c|c}
\hline \multirow{2}{*}{ Séries } & \multicolumn{3}{|c|}{ ADF } & \multicolumn{3}{c}{ PP } \\
\cline { 2 - 7 } & $\mathrm{t}-\mathrm{ADF}$ & Defasagem & $\mathrm{OI}$ & $\mathrm{t}-\mathrm{PP}$ & Bandwidth & $\mathrm{OI}$ \\
\hline TCPIB & $-6.22^{*}$ & 2 & $\mathrm{I}(0)$ & $-59.13^{*}$ & 44 & $\mathrm{I}(0)$ \\
TCREF & -0.72 & 2 & $\mathrm{I}(1)$ & -1.08 & 34 & $\mathrm{I}(1)$ \\
DTCREF & $-7.39^{*}$ & 0 & $\mathrm{I}(0)$ & $-5.19^{*}$ & 18 & $\mathrm{I}(0)$ \\
IPCOM & -0.69 & 2 & $\mathrm{I}(1)$ & -0.64 & 8 & $\mathrm{I}(1)$ \\
DIPCOM & $-5.92^{*}$ & 1 & $\mathrm{I}(0)$ & $-5.12^{*}$ & 21 & $\mathrm{I}(0)$ \\
XCOM & -0.93 & 3 & $\mathrm{I}(1)$ & -0.96 & 44 & $\mathrm{I}(1)$ \\
DXCOM & $-8.57^{*}$ & 2 & $\mathrm{I}(0)$ & $-11.69^{*}$ & 13 & $\mathrm{I}(0)$ \\
TCPIBEUA & $-3.62^{*}$ & 0 & $\mathrm{I}(0)$ & $-3.44^{*}$ & 5 & $\mathrm{I}(0)$ \\
\hline
\end{tabular}

Fonte: IPEADATA, MDIC.

Notas:

1) $D$ indica variável em primeira diferença.

2)* ${ }^{* *}$ ) indicam rejeição de $\mathrm{H}_{0}$ a $1 \%(5 \%)$ de significância.

3) Estimações com constante.

4) Valores críticos do ADF e PP: $1 \%(-3.59)$ e $5 \%(-2.93)$.

5) Ol indica a ordem de integração da série.

A partir dos resultados dos testes de raiz unitária, procedeu-se à escolha das defasagens dos modelos VAR, cujos resultados estão expostos na Tabela 2, na sequência.

Tabela 2: Escolha das Defasagens do VAR

\begin{tabular}{c|c|c|c|c}
\hline Sistemas & Defasagens & Log-likelihood & SC & AIC \\
\hline 01 & 04 & -498.9720 & 33.85047 & 29.46205 \\
02 & 03 & -525.3620 & 32.13661 & 28.82676 \\
03 & 02 & -544.5269 & 30.13767 & 27.88497 \\
04 & 01 & -584.0392 & 29.12737 & 27.91087 \\
\hline
\end{tabular}

Fonte: Elaboração própria a partir dos resultados do Eviews 5.1.

Todos os modelos VAR foram estimados utilizando-se, inicialmente, quatro defasagens. A escolha dos modelos mais adequados foi realizada tomando-se por base os valores mais baixos apresentados pelo critério de informação de Schwarz. ${ }^{2}$

${ }^{2}$ Uma vez que houve divergências entre os resultados produzidos pelos critérios de informação 
Procedendo desta forma, foi escolhido o sistema VAR com uma defasagem, chamado VAR (1). Em adição, testes de diagnósticos de resíduos foram efetuados para confirmar a real defasagem dos modelos, sendo que os resultados corroboraram as defasagens sugeridas pelo critério de Schwarz.

\section{Funções de resposta aos impulsos e análise de decomposição de variância}

A estimação das Funções de Resposta aos Impulsos e a Análise de Decomposição de Variância dos erros de previsão envolvem a avaliação de uma possível evidência sobre doença holandesa no Brasil por meio da percepção de três efeitos principais:

I. Importância de DXCOM sobre DTCREF: efeito direto da mudança das exportações de commodities sobre a taxa de câmbio real efetiva. Esta análise consiste na investigação do efeito sobre o lado real da doença holandesa, com impacto sobre a taxa de câmbio real.

II. Importância de DIPCOM sobre a DTCREF: efeito indireto em um contexto onde os preços mais altos das commodities estimulam as exportações deste tipo de produto em países abundantes em recursos naturais. Este seria o lado nominal (choque exógeno via preços internacionais das commodities) da doença holandesa, com impacto sobre a taxa de câmbio real.

III. Importância de DXCOM sobre TCPIB: efeito das alterações das exportações de commodities sobre o desempenho da economia, sinalizando um efeito perverso, dado o incentivo para a migração de recursos para os setores intensivos em recursos naturais (em que vigoram vantagens comparativas) em detrimento dos setores intensivos em tecnologia, que são mais dinâmicos e dotados de maior capacidade de estimular a taxa de crescimento do PIB. ${ }^{3}$

Sabendo que as FIR são sensíveis em relação à ordem das variáveis inseridas no VAR, optou-se por estimar a Generalized Impulse-Response Function (GIR), ou

de Akaike e Schwarz, optou-se por escolher este último critério, considerando que, segundo Enders (2004), o mesmo possui propriedades superiores e sempre seleciona um modelo mais parcimonioso do que o critério de Akaike, que tende a ser viesado para escolher um modelo mais superparametrizado.

${ }^{3}$ Cabe ressaltar as limitações do modelo, especialmente na análise do Efeito III, pois é difícil entender as mudanças no crescimento do PIB com um modelo que desconsidera outras variáveis relevantes, tais como capital humano, tecnologia, inflação, gastos do governo. Porém, destaca-se que o objetivo deste trabalho não é entender os determinantes do crescimento do PIB brasileiro, mas sim verificar a importância relativa das exportações de commodities sobre o comportamento da taxa de câmbio real e do crescimento da economia em um ambiente de flutuação cambial. 
seja, as funções de resposta aos impulsos generalizadas simples, pois, neste caso, os resultados não são afetados pela ordenação das variáveis nos sistemas. ${ }^{4}$

Levando em conta que o objetivo do trabalho é investigar a hipótese de doença holandesa em termos da relação entre exportações de commodities e apreciação cambial, e o papel das commodities para o crescimento econômico brasileiro, a Figura 1 apresenta os resultados da GIR relacionados às respostas do câmbio em relação às exportações (Efeito I) e aos preços das commodities (Efeito II), e as respostas da taxa de crescimento do PIB às exportações de commodities (Efeito III).

As funções de resposta da taxa de câmbio real aos choques das exportações de commodities (Efeito I) indicam que o câmbio responde de forma inversa às variações das exportações de commodities, com efeitos duradouros no tempo. Tal resultado sugere que a maior participação das commodities nas exportações implica apreciação da taxa de câmbio real, o que fornece uma evidência favorável à hipótese da doença holandesa no Brasil.

Quanto aos impactos dos preços das commodities sobre o câmbio (Efeito II), verifica-se que os choques dos preços daqueles bens afetam de forma positiva a taxa de câmbio real até o terceiro trimestre, sendo que, a partir daí, a taxa de câmbio real passa a responder de maneira negativa ao longo do tempo. Isso significa que os preços das commodities implicam apreciação cambial após certa defasagem temporal.

A resposta da taxa de crescimento do PIB às mudanças das exportações de commodities (Efeito III) é positiva no primeiro trimestre, mas se torna negativa no segundo trimestre. A partir daí, a resposta da taxa de crescimento do PIB é volátil aos choques das exportações de commodities. Portanto, é possível abstrair que o aumento da participação das exportações de commodities contribui para menores taxas de crescimento da economia, embora tais efeitos sejam perceptíveis com alguma defasagem temporal e tenham pouca duração no tempo.

Uma avaliação mais completa das GIR indica que a resposta da taxa de crescimento do PIB nacional é inversa aos choques de demanda externa, porém tais efeitos têm curta duração. Por outro lado, os choques cambiais influenciam a taxa de crescimento econômico de forma positiva no primeiro trimestre. Em outras palavras, uma taxa de câmbio real mais depreciada parece beneficiar o desempenho econômico, embora este efeito oscile no tempo. Tal evidência parece corroborar a literatura que sugere a importância de uma taxa de câmbio mais competitiva para estimular o desempenho econômico no curto prazo.

As GIR também permitem obter algumas indicações sobre os fatores explicativos do desempenho das exportações brasileiras de commodities. Neste caso, obtém-se que as exportações de commodities respondem negativamente aos choques da demanda externa no primeiro trimestre. No entanto, as exportações reagem positivamente aos choques de demanda externa com alguma defasagem temporal, e se estabilizam em patamar mais elevado ao longo do tempo. Disto, verifica-se

\footnotetext{
${ }^{4}$ Para maiores informações, ver Pesaran e Shin (1998).
} 

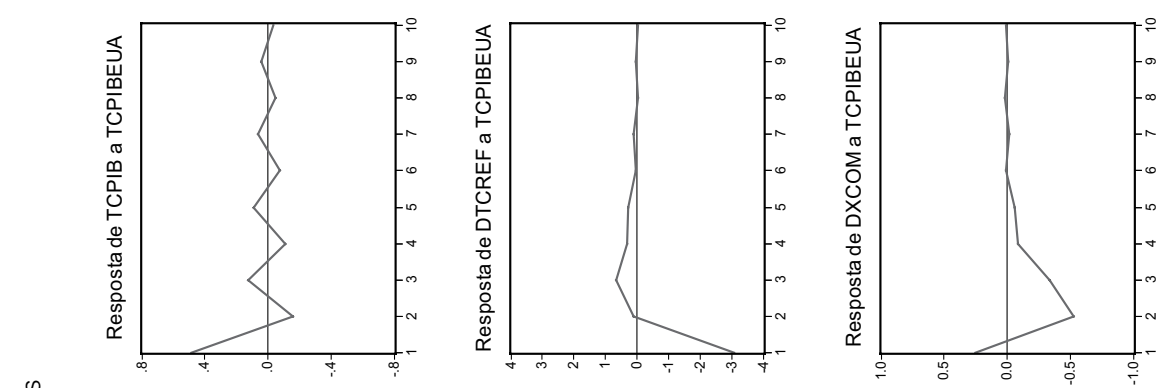

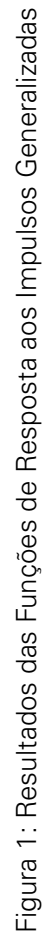
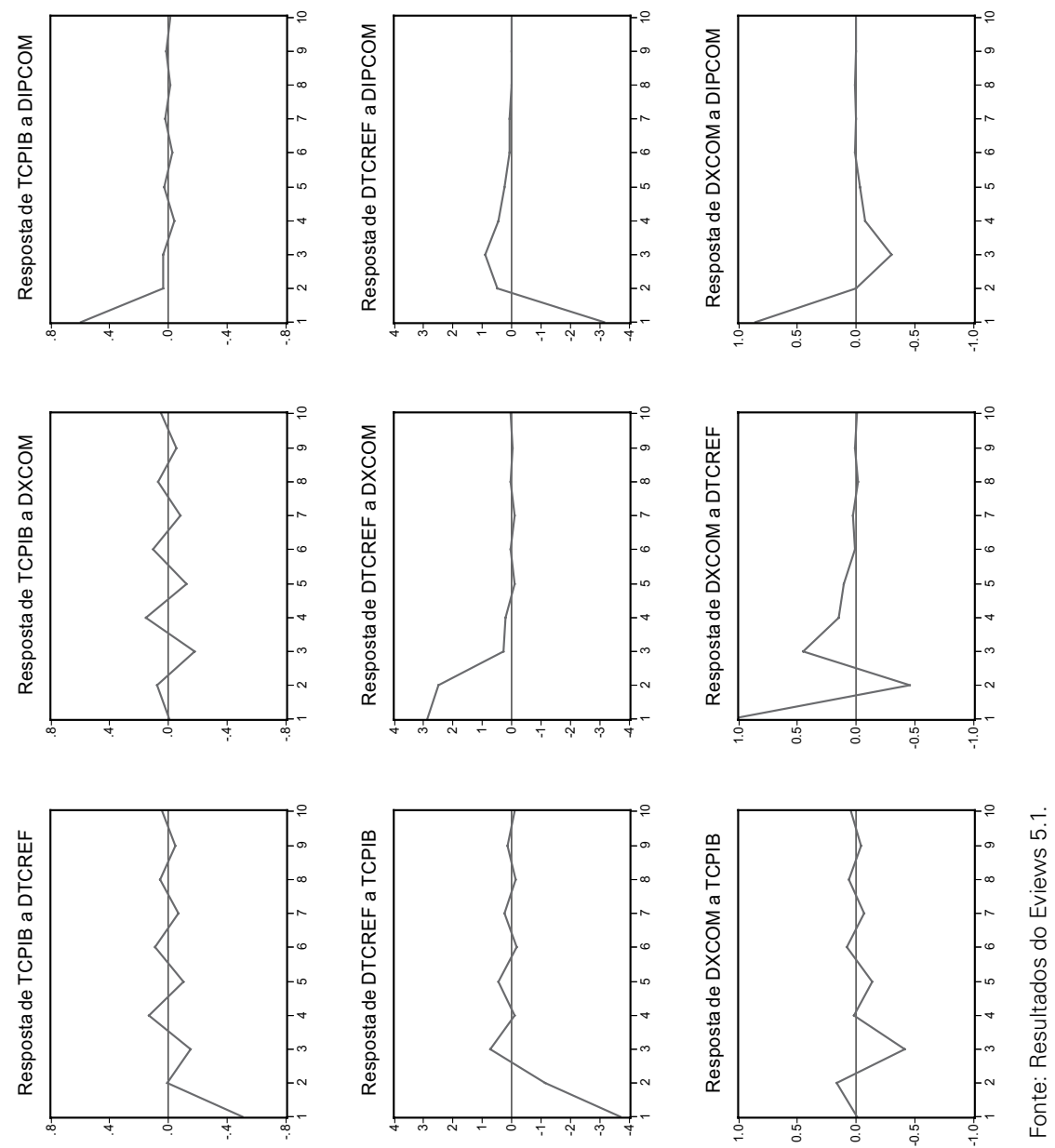
alguma importância de fatores relacionados à demanda mundial para explicar o comportamento das exportações destes bens.

As exportações de commodities inicialmente respondem inversamente às mudanças dos preços destes produtos, mas se elevam com o aumento dos preços a partir do terceiro trimestre. Ou seja, os choques de preços de commodities parecem estimular as exportações destes bens com alguma defasagem temporal.

Finalmente, as exportações de commodities têm uma resposta imediata negativa às mudanças no câmbio real, indicando que uma apreciação cambial favorece as exportações destes produtos. Este efeito sofre uma reversão no segundo trimestre, mas, no decorrer do tempo, a ampliação da participação dos produtos intensivos em recursos naturais parece estar associada a uma apreciação cambial. Em outros termos, uma apreciação da taxa de câmbio real parece estimular uma especialização das exportações em commodities, evidência coerente com os argumentos teóricos da doença holandesa.

Para a Análise de Decomposição de Variância (ADV), este trabalho se valeu da realização do teste de causalidade e exogeneidade de Granger/Block como uma melhor aproximação para definir um ordenamento estatisticamente consistente das variáveis no VAR. Este teste calcula a significância conjunta de cada variável endógena defasada para cada equação do VAR, além de fornecer a significância conjunta (linha Total da tabela) de todas as variáveis endógenas defasadas para cada uma das equações. Dessa forma, a ordenação das variáveis no VAR foi efetivada com base na estatística qui-quadrado $\chi^{2}$ ), sendo que as variáveis mais exógenas possuem valores menores para esta estatística, enquanto as mais endógenas possuem valores maiores.

Tabela 3: Testes de Causalidade Granger/Block e Exogeneidade Wald

\begin{tabular}{l|c|c|c|c|c|c|c|c|c|c}
\hline \multirow{2}{*}{} & \multicolumn{2}{|c|}{ TCPIB } & \multicolumn{2}{c|}{ DTCREF } & \multicolumn{2}{c|}{ DXCOM } & \multicolumn{2}{c|}{ DIPCOM } & \multicolumn{2}{c}{ TCPIBEUA } \\
\cline { 2 - 11 } & $\chi^{2}$ & Prob. & $\chi^{2}$ & Prob. & $\chi^{2}$ & Prob. & $\chi^{2}$ & Prob. & $\chi^{2}$ & Prob. \\
\hline TCPIB & & & 1.185 & 0.2763 & 0.347 & 0.5555 & 0.001 & 0.9734 & 0.771 & 0.3800 \\
DTCREF & 2.261 & 0.1326 & & & 0.306 & 0.5801 & 0.139 & 0.7086 & 4.594 & 0.0321 \\
DXCOM & 0.079 & 0.7781 & 0.552 & 0.4573 & & & 1.022 & 0.3120 & 0.427 & 0.5134 \\
DIPCOM & 3.329 & 0.0680 & 0.559 & 0.4543 & 0.562 & 0.4531 & & & 0.507 & 0.4762 \\
TCPIBEUA & 0.499 & 0.4798 & 0.361 & 0.5479 & 4.068 & 0.0437 & 0.001 & 0.9709 & & \\
\hline Total & 9.579 & 0.0481 & 4.147 & 0.3865 & 4.495 & 0.3432 & 1.659 & 0.7982 & 8.921 & 0.0631 \\
\hline Ranking & \multicolumn{2}{|c|}{$5^{\circ}}$. & \multicolumn{2}{|c|}{$2^{\circ}}$. & \multicolumn{2}{c|}{$3^{\circ}}$. & \multicolumn{2}{c}{$1^{\circ}}$. & \multicolumn{2}{|c}{$4^{\circ}}$. \\
\hline
\end{tabular}

Fonte: Elaboração própria a partir dos resultados do Eviews 5.1.

* O ranking de exogeneidade segue uma ordem crescente $\left(1^{\circ}=\right.$ mais exógeno $)$.

A Tabela 3 sistematiza os resultados do teste de causalidade e exogeneidade de Granger/Block. Assim, foi estabelecida a seguinte ordenação das variáveis no VAR (das mais endógenas para as mais exógenas):

Modelo VAR = TCPIB TCPIBEUA DXCOM DTCREF DIPCOM 
A partir da especificação do modelo VAR, procedeu-se à estimação da ADV, cujos resultados são apresentados pela Tabela 4 .

Quanto ao Efeito I, as evidências obtidas indicam que as variações das exportações de commodities explicam $18 \%$ das variações da taxa de câmbio real, o que sugere uma importância significativa das commodities para a explicação do comportamento cambial. Quanto ao Efeito II, os choques dos preços internacionais das commodities explicam 1,7\% dos movimentos da taxa de câmbio real. Tais resultados, aliados às evidências obtidas pelas funções de resposta aos impulsos, podem ser considerados indicativos de doença holandesa no Brasil, dado que a importância conjunta das exportações de commodities totais e dos preços das mesmas explica cerca de $20 \%$ das variações cambais no período 1999-2010, sendo verificado um impacto negativo das exportações e dos preços das commodities (este último com alguma defasagem) sobre a mudança da taxa de câmbio real.

Sobre o Efeito III, admitindo as possíveis limitações do modelo, obtém-se que os choques das exportações de commodities explicam cerca de $3 \%$ das variações da taxa de crescimento do PIB real. De outro lado, verifica-se que as variações da taxa de câmbio real e dos preços das commodities se mostram relativamente mais importantes, explicando, respectivamente, $5,9 \%$ e $6,4 \%$ das alterações do crescimento do produto real brasileiro. Destaca-se que $83,2 \%$ das variações do produto real são explicadas por choques de outras variáveis não incluídas no modelo.

Tabela 4: Análise de Decomposição de Variância

\begin{tabular}{c|c|c|c|c|c|c}
\hline \multicolumn{7}{c}{ Decomposição de Variância de TCPIB: } \\
\hline Período & S.E. & TCPIB & TCPIBEUA & DXCOM & DTCREF & DIPCOM \\
\hline 1 & 1.14 & 100.00 & 0.00 & 0.00 & 0.00 & 0.00 \\
5 & 1.65 & 84.13 & 1.48 & 2.37 & 5.79 & 6.22 \\
10 & 1.75 & 83.20 & 1.67 & 2.89 & 5.86 & 6.38 \\
\hline
\end{tabular}

Decomposição de Variância de DXCOM:

\begin{tabular}{c|c|c|c|c|c|c}
\hline Período & S.E. & TCPIB & TCPIBEUA & DXCOM & DTCREF & DIPCOM \\
\hline 1 & 3.08 & 0.00 & 0.85 & 99.15 & 0.00 & 0.00 \\
5 & 3.32 & 2.03 & 5.14 & 90.13 & 1.52 & 1.18 \\
10 & 3.33 & 2.19 & 5.14 & 89.95 & 1.54 & 1.19 \\
\hline
\end{tabular}

Decomposição de Variância de DTCREF:

\begin{tabular}{c|c|c|c|c|c|c}
\hline Período & S.E. & TCPIB & TCPIBEUA & DXCOM & DTCREF & DIPCOM \\
\hline 1 & 8.38 & 19.53 & 3.97 & 13.20 & 63.31 & 0.00 \\
5 & 9.21 & 18.63 & 4.14 & 18.02 & 57.52 & 1.69 \\
10 & 9.22 & 18.74 & 4.15 & 17.99 & 57.41 & 1.71 \\
\hline
\end{tabular}

Ordem de Cholesky:TCPIBTCPIBEUA DXCOM DTCREF DIPCOM

Fonte: Resultados do Eviews 5.1. 
Em linhas gerais, estas evidências sugerem que a especialização das exportações em bens intensivos em recursos naturais contribui para esclarecer o desempenho da economia brasileira no período recente. Este resultado pode ser comparado com o caso de outras economias emergentes, como a China, que vem se destacando, dentre outras coisas, por uma mudança do padrão de especialização exportadora na direção de produtos de conteúdo tecnológico sofisticado. Levando em conta que os impactos das exportações de commodities (embora com alguma defasagem) e dos preços daqueles produtos sobre a taxa de crescimento do PIB real através das funções de resposta aos impulsos foram negativos, estas evidências contribuem para o argumento de que a especialização das exportações em commodities desfavorece o crescimento econômico ("maldição" dos recursos naturais).

Os resultados da ADV também permitem obter algumas indicações sobre os fatores explicativos do comportamento das exportações brasileiras de commodities. Nesta direção, verifica-se certo papel dos choques da demanda externa (5\%) para explicar as mudanças das exportações de commodities, enquanto as variações dos preços internacionais e da taxa de câmbio real efetiva se mostram menos significativas, explicando, em conjunto, menos de $3 \%$ das mudanças de participação das commodities no total exportado pela economia. De fato, as evidências sugerem que $90 \%$ das variações das exportações de commodities são explicadas pelos choques da própria variável, que reflete os fatores não explicados neste modelo.

\section{CONSIDERAÇÕES FINAIS}

O perfil da estrutura produtiva e exportadora das economias especializadas em produtos intensivos em recursos naturais tem sido bastante discutido pela literatura econômica, tendo em vista os efeitos destes produtos sobre o comportamento da taxa de câmbio real e do crescimento econômico. Nestes termos, alguns estudos argumentam que as exportações de commodities, isto é, de produtos intensivos em recursos naturais em bruto e/ou com baixo grau de processamento industrial, nos quais os países possuem vantagens comparativas, causam apreciação da taxa de câmbio real ("sintoma" de doença holandesa), o que, por sua vez, acaba prejudicando o desenvolvimento dos setores produtores de bens manufaturados, que perdem competitividade no cenário internacional em virtude do câmbio apreciado. Em consequência, a concentração das exportações em commodities colabora para a obtenção de menores taxas de crescimento econômico no longo prazo, dado o baixo conteúdo tecnológico e valor agregado destes bens quando comparados aos produtos industriais.

Neste âmbito, alguns trabalhos (alguns dos quais foram revisados neste estudo) sugerem que países ricos em recursos naturais tendem a possuir menores taxas de crescimento econômico no longo prazo ("maldição" dos recursos naturais). Para resolver este dilema, propõe-se a sustentação das taxas de câmbio reais em patamares mais competitivos para estimular as exportações dos produtos manufaturados, além da adoção de medidas que visem alterar o perfil das exportações na di- 
reção de produtos de maior conteúdo tecnológico se o escopo das economias consiste em obter taxas de crescimento do produto mais elevadas e sustentadas no longo prazo.

Os dados de comércio exterior da economia brasileira revelam uma alta participação das commodities no total exportado e a vigência de uma taxa de câmbio em patamares mais apreciados no período recente. A partir desta conjuntura, o presente trabalho desenvolveu um modelo simples baseado na metodologia de Vetores Auto-Regressivos, Funções de Resposta aos Impulsos e Análise de Decomposição de Variância, que permitisse investigar as relações entre taxa de câmbio real, exportações de commodities e crescimento da economia brasileira no período 1999-2010.

A análise empírica apontou algumas evidências favoráveis à hipótese de doença holandesa no Brasil naquele período em termos de uma importância expressiva dos fluxos de exportação de commodities para a explicação do comportamento da taxa de câmbio real. O padrão de especialização das exportações em commodities junto com os preços destes produtos (ainda que se leve em conta as limitações do modelo) também se mostrou relevante para explicar um desempenho econômico menos favorável do país. Ademais, verificou-se a importância de uma taxa de câmbio mais desvalorizada para estimular o crescimento de curto prazo do produto real brasileiro. Tais evidências fornecem certo suporte aos argumentos da literatura sobre a "maldição" dos recursos naturais.

Finalmente, uma conjuntura internacional favorável em termos das variações positivas dos preços internacionais das commodities e da demanda externa foram fatores relevantes para estimular a especialização das exportações brasileiras em produtos intensivos em recursos naturais, embora este resultado envolva certa defasagem temporal. A apreciação cambial também se mostrou relacionada à especialização das exportações em commodities. Tais evidências parecem condizentes com os "sintomas" de doença holandesa, conforme aponta a literatura pertinente.

\section{REFERÊNCIAS BIBLIOGRÁFICAS}

AGUIRRE, A.; CALDERÓN, C. (2005) Real exchange rate misalignments and economic performance. Central Bank of Chile, Working Papers $\mathrm{N}^{\circ} 315$. April.

BERG, A.; MIAO, Y. (2010) “The real exchange rate and growth revisited: The Washington Consensus strikes back?” IMF Working Paper, Research Department and African Department, March. Disponível em: http://www.imf.org/external/pubs/ft/wp/2010/wp1058.pdf. Acesso em Agosto de 2010.

BCB. Banco Central do Brasil (2010) Economia e Finanças. Séries Temporais. Disponível em: http:// www4.bcb.gov.br/?SERIESTEMP. Acesso em Junho de 2010.

BRESSER-PEREIRA, L. C. (2008) “The Dutch disease and its neutralization: a Ricardian approach", Revista de Economia Política, Vol. 28, nº 1 (109), p. 47-71.

BRESSER-PERREIRA, L. C. (2009) Globalização e Competição: Por que alguns países emergentes têm sucesso e outros não. Rio de Janeiro: Elsevier.

CARDOSO, E.; HOLLAND, M. (2009) "South America for the Chinese? A trade-based analysis". Paris, França: OECD. Working Paper. 
COLLIER, P.; GODERIS, B. (2007) "Commodity prices, growth and the natural resources curse: Reconciling a Conundrum”. Working Paper 276. Centre for the Study of African Economies. August.

DALUM, B.; LAURSEN, K; VERSPAGEN, B. (2008) “Does specialization matters for growth?”, October. 1996. Disponível em: http://www.meritbbs.unimas.nl/tser/tserhtml. Acesso em Maio de 2008.

EICHENGREEN, B. (2008) "Real exchange rate and economic growth", Working Paper No. 4. Commission on Growth and Development, World Bank, Washington, DC.

ENDERS, W. (2004) Applied Econometric Time Series. New York: Wiley, 2 ${ }^{\text {nd }}$. edition.

GALA, P. S. O. S. (2006) "Política cambial e macroeconomia do desenvolvimento", Tese de Doutorado em Economia. Escola de Administração de Empresas de São Paulo da Fundação Getulio Vargas. São Paulo. Disponível em: http://www.eumed.net/tesis/2007/psosg/. Acesso em Setembro de 2009.

HAUSMANN, R.; HWANG, J.; RODRIK, D. (2005) "What you export matters”, NBER Working Paper, December.

IFS. (2009) International Financial Statistics Database. CD-ROM, International Monetary Fund (IMF), Washington, DC, January.

IPEADATA (2010) Banco de Dados do Instituto de Pesquisa em Economia Aplicada (IPEA). Estatísticas Macroeconômicas. Disponível em: http://www.ipeadata.gov.br/ipeaweb.dll/ipeadata?192810671. Acesso em Junho de 2010.

LEDERMAN, D.; MALONEY, W. F. (2008) “In search of the missing resource curse”, Policy Research Working Paper 4766. World Bank, Washington, DC., November.

MDIC. Ministério do Desenvolvimento, Indústria e Comércio Exterior. Estatísticas de Comércio Exterior (DEPLA). Balança Comercial Brasileira Mensal. Disponível em: http://www.desenvolvimento.gov.br/sitio/interna/interna.php?area=5\&menu=1161. Acesso em Junho de 2010.

OREIRO, J. L.; FEIJÓ, C. A. (2010) “Desindustrialização: conceituação, causas, efeitos e o caso brasileiro. Revista de Economia Política, Vol. 30, n. 2.

PESARAN, H. H.; SHIN, Y. (1998) " Generalized impulse response analysis in linear multivariate models”, Economics Letters, Vol. 58, n. 1, p. 17-29.

RAZIN, O.; COLLINS, S. M. (1997) "Real exchange rate misalignments and growth”, NBER Working Paper Series, No. 6174. September. Disponível em: http://www.nber.org/papers/w6174.pdf. Acesso em Agosto de 2010.

RODRIK, D. (2006) “What is so special about China's exports?”, NBER Working Paper Series, No. 11947, January.

RODRIK, D. (2008) "The real exchange rate and economic growth", Brookings Papers on Economic Activity. Disponível em: http://www.brookings.edu/ /media/Files/Programs/ES/BPEA/2008_fall_ bpea_papers/2008_fall_bpea_rodrik.pdf. Acesso em Julho de 2010.

SACHS, J. D.; WARNER A. M. (1995) “Natural resource abundance and economic growth", National Bureau of Economic Research, NBER Working Paper No. 5398. December. Disponível em: http:// www.nber.org/papers/w5398. Acesso em Setembro de 2009.

STOCK, J.; WATSON, M. Vector (2001) “Autoregression”, Journal of Economic Perspectives, 15(4), March. 